NASA

Technical Memorandum 107451
Army Research Laboratory Technical Report ARL-TR-1370

\title{
Computerized Simulation of Meshing of Conventional Helical Involute Gears and Modification of Geometry
}

F.L. Litvin and J. Lu

University of Illinois at Chicago

Chicago, Illinois

D.P. Townsend

Lewis Research Center

Cleveland, Ohio

M. Hawkins

Allison Engine Company

Indianapolis, Indiana

July 1997

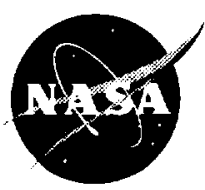

National Aeronautics and

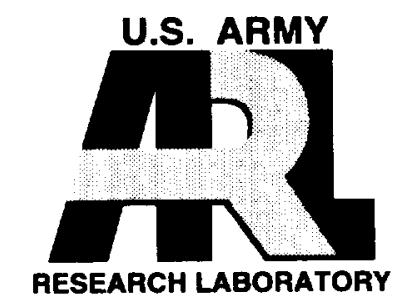





\title{
COMPUTERIZED SIMULATION OF MESHING OF CONVENTIONAL HELICAL INVOLUTE GEARS AND MODIFICATION OF GEOMETRY
}

\author{
F.L. Litvin ${ }^{\star}$ and J. Lu' ${ }^{\dagger}$ \\ The University of Illinois at Chicago \\ Chicago, Illinois 60680 \\ D.P. Townsend ${ }^{\ddagger}$ \\ National Aeronautics and Space Administration \\ Cleveland, Ohio 44135 \\ and \\ M. Hawkins $\$$ \\ Allison Engine Company \\ Indianapolis, IN 46206
}

\section{ABSTRACT}

An approach is proposed for computerized simulation of meshing of aligned and misaligned involute helical gears. Algorithms for TCA (Tooth Contact Analysis) computer programs were developed. Influence of misalignment on the shift of the bearing contact and transmission errors has been investigated. Numerical examples that illustrate the developed theory are provided.

\section{NOMENCLATURE}

$\begin{array}{ll}\alpha_{c} & \text { parabola coefficient of function that represents the tooth profile of pinion rack-cutter (Fig. 10) } \\ H_{i} & \text { gear ratio } \\ m_{21} & \left.\text { coordinate transformation matrix (from } S_{j} \text { to } S_{i}\right) \\ M_{i j} & \text { unit normal vector to surface } \Sigma_{i} \text { represented in coordinate system } S_{f} \\ n_{f}^{(i)}(i=1,2) \quad \text { unit normal to surface } \Sigma_{i} \\ n_{i}\left(\theta_{i}\right)(i=1,2) \quad \text { nooth number of the pinion }(i=1) \text { or the gear }(i=2) \\ N_{i} \\ N_{r} \quad \text { screw parameter } \\ p_{i}(i=1,2) \quad \text { circular pitch in transverse section } \\ p_{t i}(i=1,2) \quad \text { normal diametral pitch } \\ P_{n}\end{array}$

*Dr., Professor, ASME Fellow.

${ }^{\dagger}$ Dr., ASME Member.

${ }^{\ddagger}$ ASME Fellow.

$\$$ ASME Member. 


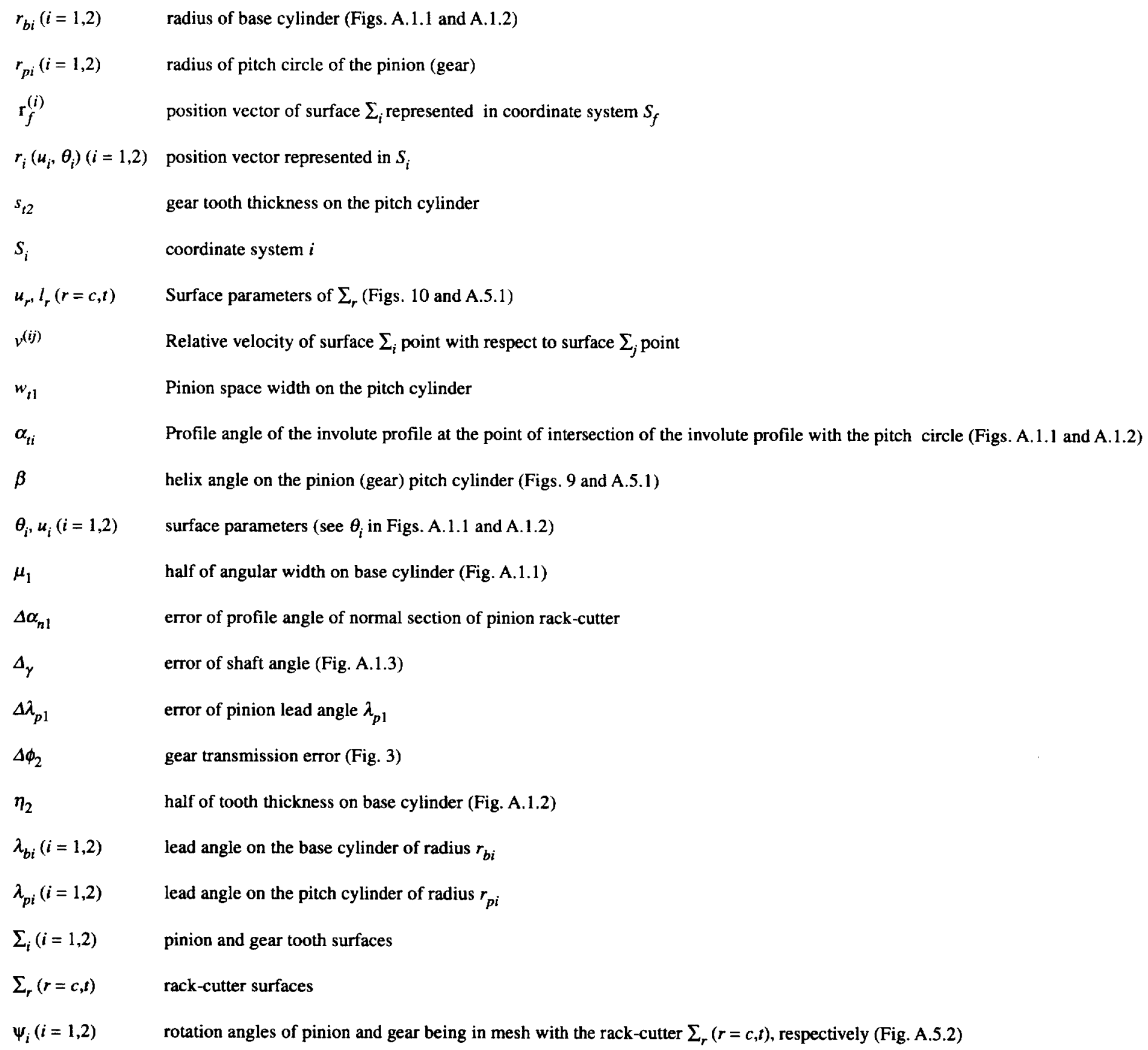

\section{INTRODUCTION}

Computerized simulation of meshing and contact (Tooth Contact Analysis - TCA) was developed for spiral bevel and hypoid gear drives with tooth surfaces are in point contact, (User's Manual, Litvin, F.L. and Gutman, Y., 1981, Litvin, F.L., et al., 1995, and Stadtfeld, H.J., 1993.) There is a great need to develop TCA computer programs for tooth surfaces that are initially in line contact that become point contact due to misalignment. A typical example of such gear drives is the conventional involute helical gear drive.

An approach is proposed that permits the investigation of the influence of gear misalignment on the shift of the bearing contact and transmission errors. Effective methods of crowning of gear tooth surfaces are proposed. The approach is complemented with a TCA computer program. Numerical examples that illustrate the developed approach are provided. 


\section{SIMULATION OF MESHING}

\section{General Considerations}

For simulation of meshing, coordinate systems $S_{1}$ and $S_{2}$ that are rigidly connected to pinion 1 and gear 2, respectively (Fig. A.1.3), are applied. The meshing, of the gear tooth surfaces is considered in the fixed coordinate system $S_{f}$ that is rigidly connected to the housing. Coordinate system $S_{p}$ is an auxiliary fixed coordinate system. Coordinate system $S_{q}$ is applied to simulate misalignment (Fig. A.1.3). Gear tooth surface $\sum_{i}(i=1,2)$ of a helical gear and the surface unit normal are represented in $S_{i}$ by vector functions $\mathbf{r}_{i}\left(u_{i}, \theta_{1}\right)$ and $\mathbf{n}_{i}\left(\theta_{1}\right)$, respectively, where $\left(u_{i}, \theta_{1}\right)$ are the surface parameters (see Appendix 1). Using coordinate transformation from $S_{i}$ to $S_{f}$ we represent the conditions of continuous tangency of gear tooth surfaces by following vector Eqs.(2-5).

$$
\begin{gathered}
\mathbf{r}_{f}^{(1)}\left(u_{1}, \theta_{1}, \phi_{1}\right)-\mathbf{r}_{f}^{(2)}\left(u_{2}, \theta_{2}, \phi_{2}\right)=0 \\
\mathbf{n}_{f}^{(1)}\left(\theta_{1}, \phi_{1}\right)-\mathbf{n}_{f}^{(2)}\left(\theta_{2}, \phi_{2}\right)=0
\end{gathered}
$$

Vector Eqs. (1) and (2) yield only five independent equations

$$
f_{i}\left(u_{1} \theta_{1}, \phi_{1}, u_{2}, \theta_{2}, \phi_{2}\right)=0 \quad f_{i} \in C^{1}(i=1,2, \ldots, 5)
$$

since

$$
\left|\mathbf{n}_{f}^{(1)}\right|=\left|\mathbf{n}_{f}^{(2)}\right|=1
$$

Equation system (3) contains six unknowns but one parameter, say $\phi_{1}$, may be chosen as input. The continuous solution of equation system (3) is an iterative process that is based on the following considerations:

(1) Assume that system (3) of nonlinear equations is satisfied at a point

$$
P^{(0)}=\left(u_{1}^{(0)}, \theta_{1}^{(0)}, \phi_{1}^{(0)}, u_{2}^{(0)}, \theta_{2}^{(0)}, \phi_{2}^{(0)}\right)
$$

and the Jacobian of the fifth order satisfies the requirement

$$
\Delta_{5}=\left|\frac{\partial f_{i}}{\partial u_{1}} \frac{\partial f_{i}}{\partial \theta_{1}} \frac{\partial f_{i}}{\partial u_{2}} \frac{\partial f_{i}}{\partial \theta_{2}} \frac{\partial f_{i}}{\partial \phi_{2}}\right| \neq 0 \quad(i=\overline{1,5})
$$

(2) Then we can solve Eqs. (3) in the neighborhood of $P^{(0)}$ by functions

$$
\left\{u_{1}\left(\phi_{1}\right), \theta_{1}\left(\phi_{1}\right), u_{2}\left(\phi_{1}\right), \theta_{2}\left(\phi_{1}\right), \phi_{2}\left(\phi_{1}\right)\right\} \in C^{1}
$$

(3) Inequality (6) is observed when the gear tooth surfaces are in point contact. In this case, using functions (7) we are able to obtain: (i) the path of contact on surface $\sum_{i}(i=1,2)$ represented as

$$
\mathbf{r}_{i}\left(u_{i}, \theta_{i}\right), u_{i}\left(\phi_{i}\right), \theta_{i}\left(\phi_{i}\right)
$$

and (ii) the transmission errors determined as

$$
\Delta \phi_{2}\left(\phi_{1}\right)=\phi_{2}\left(\phi_{1}\right)-\frac{N_{1}}{N_{2}} \phi_{1}
$$

The solution discussed above is found numerically. A subroutine for solution of nonlinear equations is represented in User's Manual, 1989. The approach discussed is applied for simulation of meshing of misaligned helical gears. As a reminder that due to misalignment the line contact of tooth surfaces is turned out into point contact. 


\section{Edge Contact}

Equations (1) and (2) describe continuous surface-to-surface tangency. However, it is not excluded that due to misalignment edge contact will occur that means curve-to-surface tangency when the edge of a surface of one gear (represented as a curve) will contact the surface of the mating gear. Considering the case when the edge of the pinion is in mesh with the surface of the gear, we will use the following equations

$$
\begin{gathered}
\mathbf{r}_{f}^{(1)}\left(u_{1}\left(\theta_{1}\right), \theta_{1}, \phi_{1}\right)=\mathbf{r}_{f}^{(2)}\left(u_{2} \theta_{2}, \phi_{2}\right) \\
\frac{\partial \mathbf{r}_{f}^{(1)}}{\partial \theta_{1}} \cdot \mathbf{n}_{f}^{(2)}=0
\end{gathered}
$$

Equations (10) and (11) represent a system of four nonlinear equations in four unknowns $\left(f_{1}\right.$ is considered as the input paramter). The solution to the system of Eqs. (10) and (11) allow to obtain functions

$$
\theta_{1}\left(\phi_{1}\right), \theta_{2}\left(\phi_{1}\right), u_{2}\left(\phi_{1}\right), \phi_{2}\left(\phi_{1}\right)
$$

All three cases of meshing, such as surface-to-surface with instantaneous point contact, edge contact, and line contact (see below), may exist in meshing of involute helical gears when they are misaligned or aligned.

\section{Simulation of Meshing of Aligned Helical Gears}

In this case, the gear tooth surfaces are in line ctonact and the Jacobian $\mathrm{D}_{5}$ (Eq. (6)) becomes equal to zero. The TCA is based on the algorithm represented in Appendix 3. Two input parameters, say $f_{1}$ and $u_{1}$, must be applied and then we will get that the matrix

$$
\left|\frac{\partial f_{i}}{\partial \theta_{1}} \frac{\partial f_{i}}{\partial u_{2}} \frac{\partial f_{i}}{\partial \theta_{2}} \frac{\partial f_{i}}{\partial \phi_{2}}\right| \quad(i=\overline{1,4})
$$

will be of rank 4 . THe instantaneous line of contact on surface $\sum_{i}(i=1,2)$ is the $q$-line of the vector function $\mathbf{r}_{i}\left(u_{i}, q_{i}\right)$. This line is the tangent to the helix on the base cylinder of gear $i$ (Fig. 1). Computations confirm that the transmission funciton is a linear one represented as

$$
\phi_{2}\left(\phi_{1}\right)=\frac{N_{1}}{N_{2}} \phi_{1}
$$

and the transmission errors are zero.

\section{Simulation of Meshing of Misalianed Involute Helical Gears}

The TCA computer program developed was applied to investigate of the following erros: Dg-the shaft angle error (when the axes become crossed), $\mathrm{D} a_{n 1}$ normal proifle angle error of the rack-cutter that generates the pinion, and $\mathrm{Dl}_{p 1}$-pinion lead angle error on the pitch cylinder.

The manufacturing of helical gears is based on application of two imaginary rack-cutters that like a molding complements a casting. The pinion and the gear are generated separately, but the imaginary rack-cutters have the same profile angle $a_{n}$ in the normal section. Error Da $a_{n 1}$ means that $a_{n 1} \neq a_{n 2}$.

Parameter $a_{n}$ does not exist directly in the surface and surface unit normal equations (see Appendix 1). However, error Da $a_{n 1}$ affects the design parameters $a_{t 1}, r_{b 1}$, and $\mathrm{l}_{b 1}$ as follows (see Appendix 2)

$$
\begin{gathered}
\Delta \alpha_{t 1}=\frac{\sin 2 \alpha_{t 1}}{\sin 2 \alpha_{n 1}} \Delta \alpha_{n 1} \\
\Delta \lambda_{b 1}=\frac{\sin 2 \lambda_{b 1} \tan \alpha_{t 1}}{2} \Delta \alpha_{t 1}
\end{gathered}
$$




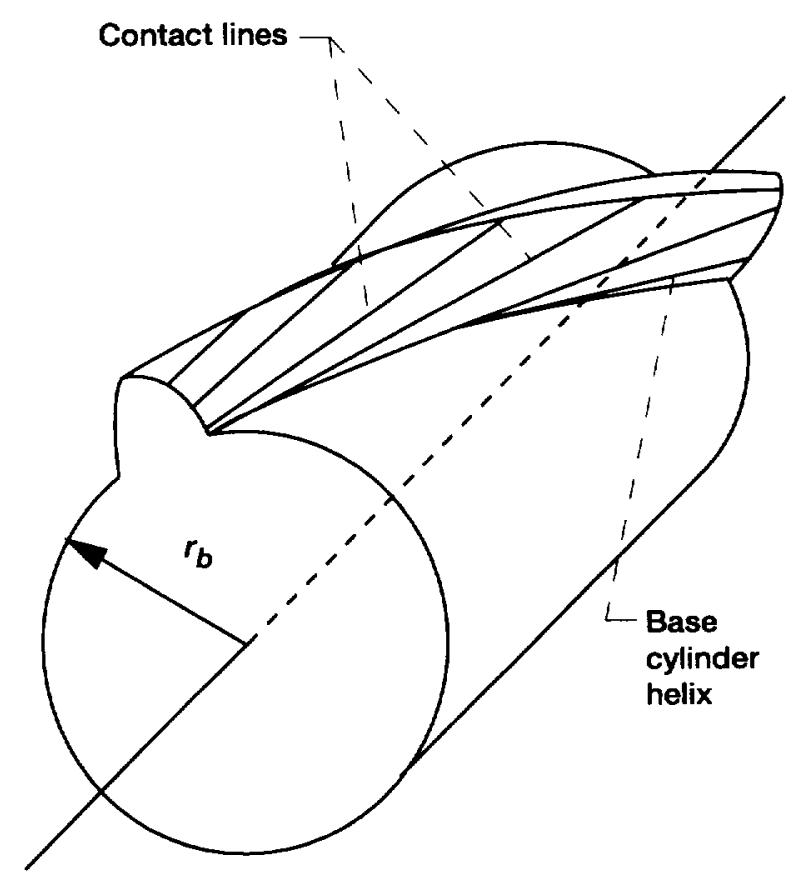

Figure 1.-Contact lines on tooth surfaces of a helical gear.

$$
\Delta r_{b 1}=-r_{p 1} \sin \alpha_{t 1} \Delta \alpha_{t 1}
$$

In the real process of manufacturing, error $\mathrm{Dl}_{p 1}$ is caused due to lead error $H_{1}$. Using the relationships between the design parameters (see Appendix 2), the following is obtained:

$$
\Delta \lambda_{p 1}=\frac{\sin 2 \lambda_{p 1}}{2 H_{1}} \Delta H_{1}
$$

Equation (18) permits $\mathrm{Dl}_{p 1}$ to be obtained considering the lead error $\mathrm{D} H_{1}$ is known.

Due to misalignment, the line contact of tooth surfaces is turned into point contact. The TCA for point contact is based on the application of equation system (3). The algorithm for initial guess for the solution of equation system (3) is represented in Appendix 4.

The influence of errors $\mathrm{Dg}, \mathrm{Da} a_{n 1}$, and $\mathrm{Dl}_{p 1}$ was investigated in the following ways: (i) as the impact by the separate action of each of the errors, and (ii) as the impact by action of the following combination of errors: $\mathrm{Dg}, \mathrm{Dl}_{p 1}$, and $\mathrm{Da} a_{n 1}$ and $\mathrm{Dl}_{p 1}$.

The separate action of errors $\mathrm{Dl}$ and $\mathrm{Dl}_{p 1}$ causes an edge contact (Fig. 2) and a discontinuous, almost linear function of transmission errors (Fig. 3). Error $\mathrm{D} a_{n 1}$ causes paths of contact shown in Fig. 4 but does not cause transmission errors. The drawings shown in Figs. 2 to 4 are based on computation for a gear drive with the following data: $N_{1}=30, N_{2}=100, a_{n}=20^{\circ}, P_{n}=5\left(1 / \mathrm{in}\right.$.), $\mathrm{I}_{p}=60^{\circ}$, and $L=1.6$ (in.).

The combination of errors $\mathrm{Dg}$ and $\mathrm{Dl}_{p 1}$ when $|\Delta \gamma| \neq\left|\Delta \lambda_{p 1}^{n}\right|$ causes also an edge contact (Fig. 5). The function of transmission errors for one cycle of meshing is a combination of two almost linear functions with different values of slope (Fig. 6). The combination of errors $\mathrm{D} a_{n 1}$ and $\mathrm{Dl}{ }_{p 1}$ causes the path of contact on the edge of the tooth length (Fig. 7) and an almost linear function of transmission errors (Fig. 8).

There is a particular case, when $|\Delta \gamma| \neq\left|\Delta \lambda_{p 1}\right|$. The meshing of gears may be considered in such a case as meshing of crossed involute helical gears which tooth surfaces are in point contact. The path of contact on the tooth surface is shown in Fig. 9, the transmission function is a linear one, and there
is no transmission errors. However, the meshing of gear is not stable because even a small difference between $|\Delta \gamma| \neq \mid \Delta \lambda$ pl will cause an edge contact and transmission errors. 


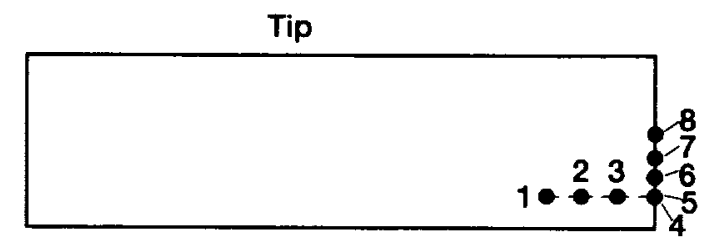

(a) Root

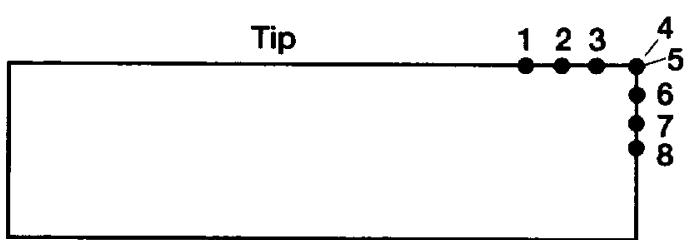

(b)

Root

Figure 2.-Edge contact caused by $\Delta \gamma$ or $\Delta \lambda_{p} l=3$ arc min: (a) pinion tooth surface, (b) gear tooth surface.

Tip

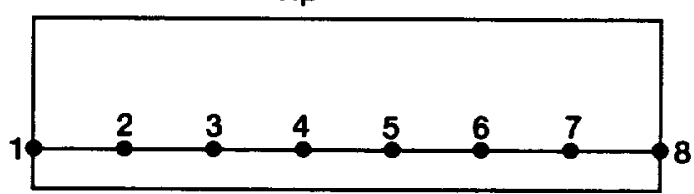

(a)

Root

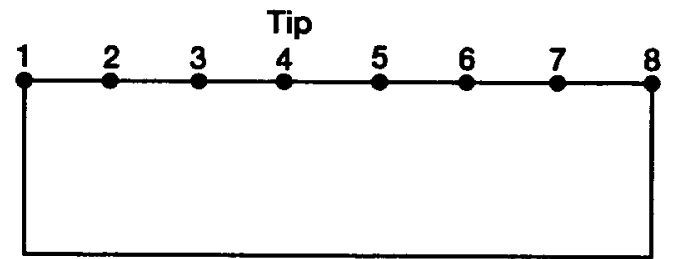

(b)

Root

Figure 4.-Path of contact caused by $\Delta \alpha n l=3$ arc min: (a) pinion tooth surface, (b) gear tooth surface.

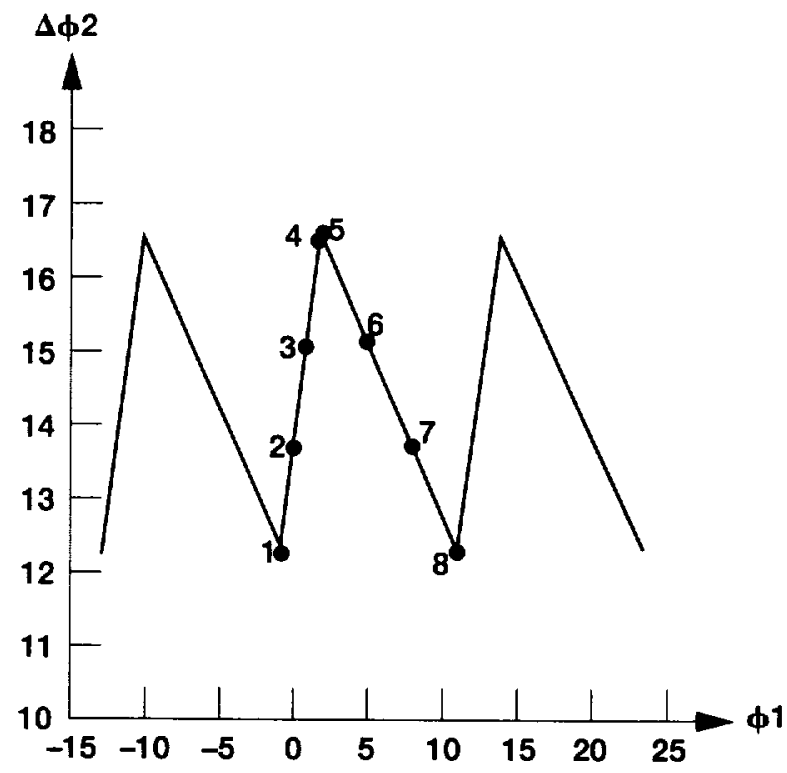

Figure 3.-Function of transmission errors caused by $\Delta \gamma$ or $\Delta \lambda_{p} l=3$ arc min.

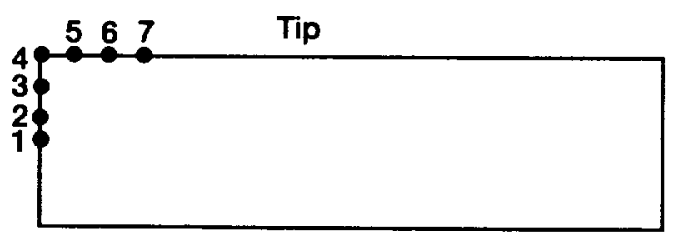

(a)

Root

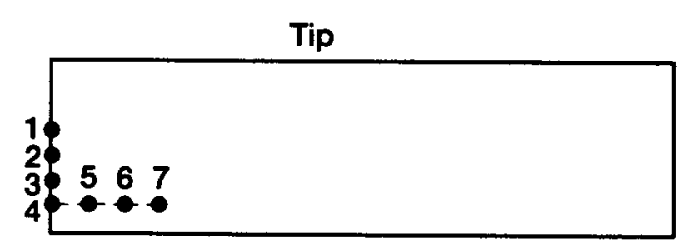

(b)

Root

Figure 5.-Edge contact caused by $\Delta \gamma=3$ arc $\min$ and $\Delta \lambda_{p} l=-4$ arc min: (a) pinion tooth surface, (b) gear tooth surface. 


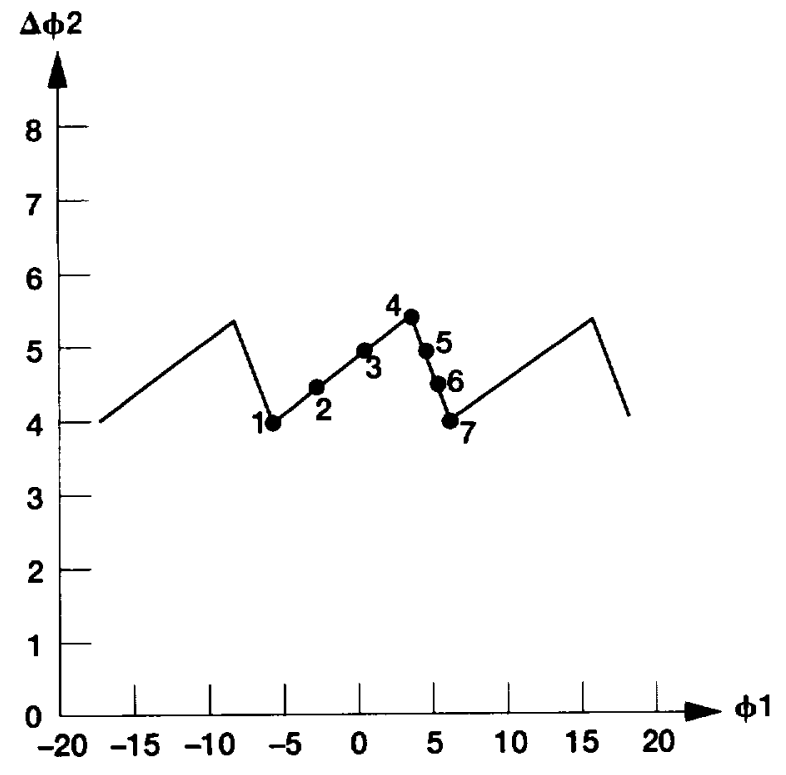

Figure 6.-Function of transmission errors caused by $\Delta \gamma=3$ arc min and $\Delta \lambda_{p} l=-4$ arc min.

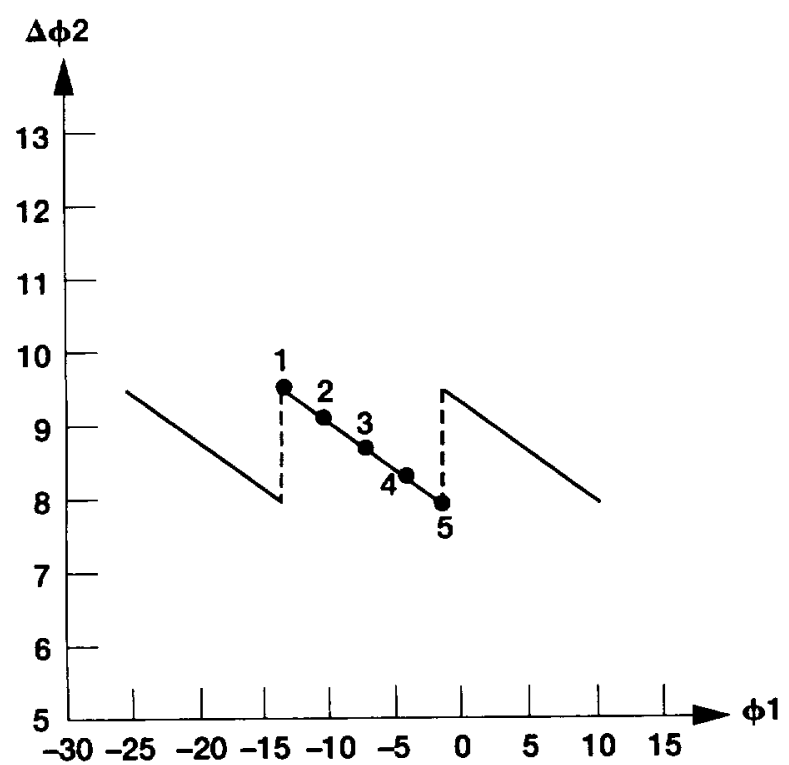

Figure 8.-Function of transmission errors caused by $\Delta \alpha n 1=3$ arc min and $\Delta \lambda_{p} l=-2$ arc min.
Tip

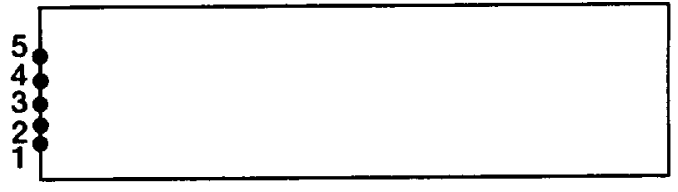

Root

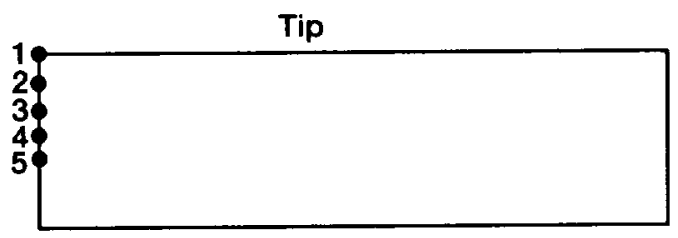

(b)

Root

Figure 7.-Edge contact caused by $\Delta \alpha n 1=3$ arc min and $\Delta \lambda_{p} l=-2$ arc min: (a) pinion tooth surface, (b) gear tooth surface.

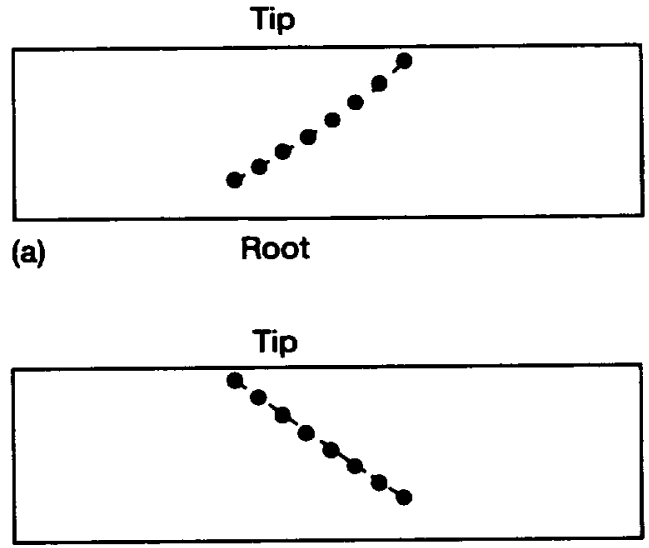

(b) Root

Figure 9.-Path of contact caused by $\Delta \gamma=3$ arc min and $\Delta \boldsymbol{\lambda}_{\mathrm{p}} \mathrm{l}=\mathbf{- 3}$ arc min: (a) pinion tooth surface, (b) gear tooth surface. 


\section{GENERATION AND MODIFICATION OF TOOTH SURFACES}

The derivation of tooth surfaces is based on the imaginary process of generation of conjugate surfaces by application of two rack-cutters. The generating surfaces of the rack-cutters are represented respectively by plane $\Sigma_{t}$ and cylindrical surface $\Sigma_{c}$ that differs slightly from plane $\Sigma_{t}$ (Fig. 10). The rack-cutter surfaces $\Sigma_{c}$ and $\Sigma_{g}$ are rigidly connected each to other in the process of the imaginary generation, and they are in tangency along straight line $o_{b} z_{b}$ (Fig. 10). This line and axes of the gears form angle $b$, that is equal to the helix angle on the pinion (gear) pitch cylinder. Figure 11 shows the normal sections of the rack-cutters. Rack-cutter surface $\Sigma_{c}$ generates the pinion tooth surface $\Sigma_{1}$, and a rack-cutter surface $\Sigma_{1}$ generates the gear tooth surface $\Sigma_{2}$.

\section{Applied Coordinate Systems}

Movable coordinate systems $S_{r}(r=c, t), S_{1}$ and $S_{2}$ are rigidly connected to the tools (rack-cutters), the pinion and the gear, respectively. The fixed coordinate systems $S_{m}$ and $S_{n}$ are rigidly connected to the frame of the cutting machine (Fig. A.5.2).

Generating Surface

The rack-cutter surface $\Sigma_{t}(r=c, t)$ is represented in $S_{r}$ by the equation

$$
\mathbf{r}_{r}=\mathbf{r}_{r}\left(u_{r}, l_{r}\right)
$$

where $u_{r}, l_{r}$ are the surface parameters.

The normal to the rack-cutter surface is represented as

$$
\mathbf{N}_{r}=\frac{\partial \mathbf{r}_{r}}{\partial l_{r}} \times \frac{\partial \mathbf{r}_{r}}{\partial u_{r}}
$$

Equations (19) and (20) must be derived twice to represent the working surfaces of two rack-cutters that generate the pinion and the gear, respectively (see Appendix 5).

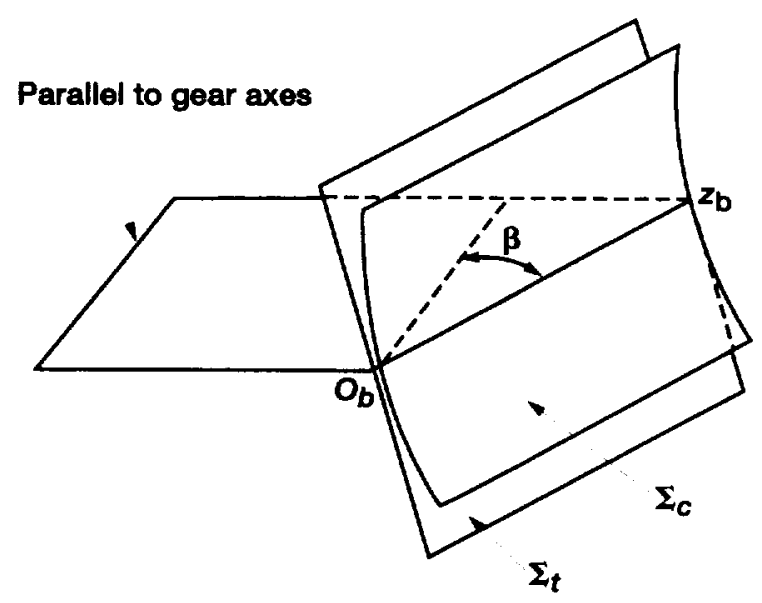

Figure 10.-Rack-cutter surfaces.

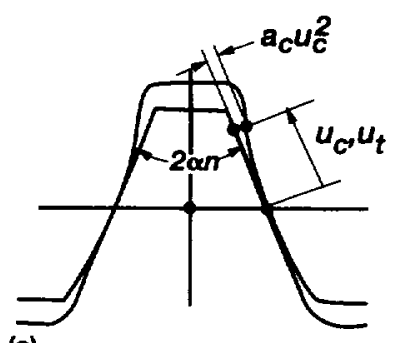

(a)

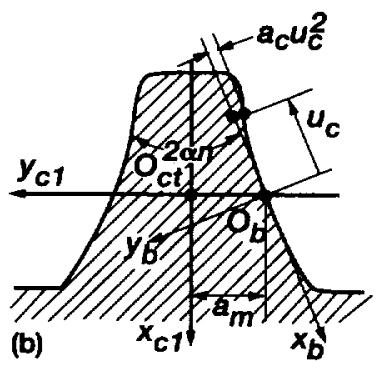

(c)

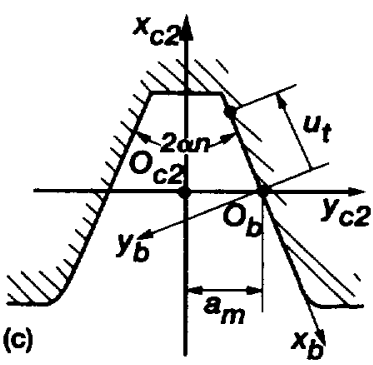

Figure 11.-Normal sections of rack-cutters. 


\section{Generated Surface}

The generated surface $\Sigma_{i}$ ( $\left.i=1,2\right)$, the pinion or the gear surface, is determined as the envelope to the family of rack-cutter surfaces. Surface $\sum_{i}$ is determined in $S_{i}$ (see Appendix 5) by the Eqs. (3) and (4).

$$
\begin{gathered}
\mathbf{r}_{i}\left(u_{r}, l_{r}, \psi_{i}\right)=\mathbf{M}_{i r}\left(\psi_{i}\right) \mathbf{r}_{i}\left(u_{r}, l_{r}\right) \\
\mathbf{N}_{r} \cdot \mathbf{v}_{r}^{(r i)}=f\left(u_{r}, l_{r}, \psi_{i}\right)=0
\end{gathered}
$$

Here: $\left(u_{r}, l_{r}\right)$ are the rack-cutter surface parameters; $y_{i}$ is the generalized parameter of motion in the process for generation; $\mathbf{N}_{r}$ is the normal to the rack-cutter surface; $v_{r}^{(r i)}$ is the relative velocity in meshing of the rack-cutter and the generated surface. Equation (21) represents in $S_{i}$ the family of rack-cutter surfaces. Equation (22) is the equation of meshing that is the necessary condition of envelope existence.

Equations (21) and (22) represent surface $\Sigma_{i}$ by three related parameters. Taking into account that $l_{r}$ is a linear parameter in equation of meshing, it can be eliminated and surface $\Sigma_{i}$ can be represented in two-parameter form, by parameters $u_{r}, y_{i}$ (see Appendix 5).

\section{Simulation of Meshing}

Using the conditions of continuous tangency of gear tooth surfaces (1) and (2), and solving the equation systems (3), we can obtain the contact path on pinion and gear tooth surfaces, respectively. Since the pinion tooth surface is modified and generated by cylindrical surface $\Sigma_{c}$ of the rack-cutter, the pinion and gear tooth surfaces are in mesh in point contact. The contact path is directed along the tooth length. Although the misalignment $\mathrm{Dg}$ occurs, the contact path is still close to the mean line. Figures 12 and 13 show the TCA results for the case of $\mathrm{Dg}=3$ arc min. Figure 12 shows that the contact path is in the middle of the pinion (gear) tooth surface and Fig. 13 shows that the function of transmission errors is an almost linear. The results of TCA confirm that the localization of contact is a necessary but not a sufficient condition of the improvement of meshing of helical gears. Due to the shape of transmission errors shown in Fig. 13, the transfer of meshing to the neighboring pair of teeth will be accompanied with high acceleration and vibration. This defect can be avoided by application of a predesigned parabolic function of transmission errors that is able to absorb the almost linear function of transmission errors (Litvin, F.L., 1994). Various methods of the predesign of a parabolic function of transmission errors were proposed in Litvin, F.L., et al., 1995.

Tip

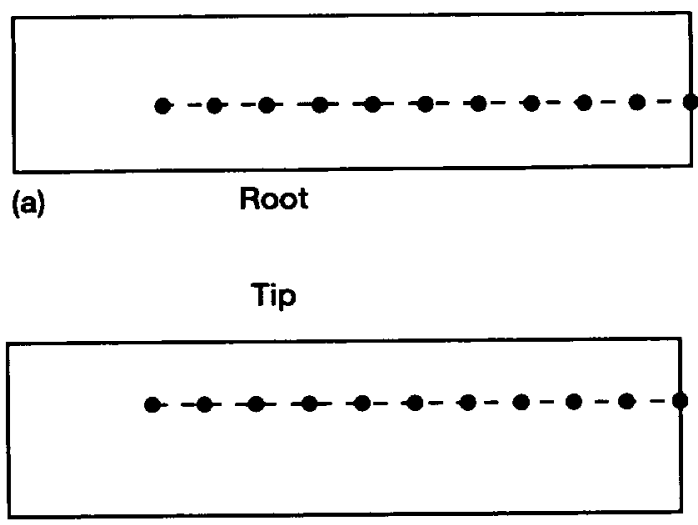

(b)

Figure 12.-Path of contact caused by $\Delta \gamma=3$ arc min: (a) modified pinion tooth surface, (b) gear tooth surface.

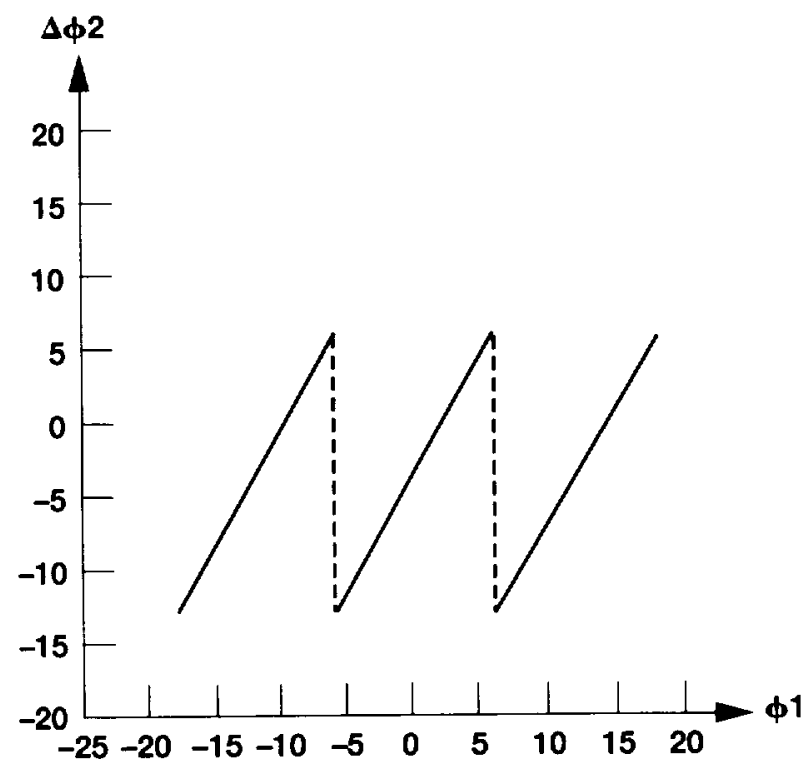

Figure 13.-Function of transmission errors for modified involute helical gear drive when $\Delta \boldsymbol{\gamma}=\mathbf{3}$ arc min. 


\section{CONCLUSION}

Based on the study contained herein the following conclusions can be drawn:

1. Equations of gear tooth surfaces with localized bearing contact were developed.

2. Algorithms for TCA (Tooth Contact Analysis) of aligned and misaligned involute helical gear drives have been developed.

3. Numerical examples that illustrate the developed theory and permit one to determine the influence of errors of alignment are presented. Lead correction may be accompanied with edge contact (Fig. 2).

\section{REFERENCES}

1. IMSL MATH/LIBRARY: User's Manual, MALB-USM-UNBND-EN 8901-1.1, 2500, Citywest B1., Houston, Texas 77042-3020, 1989.

2. Litvin, F.L. and Gutman, Y.: "Methods of Synthesis and Analysis for Hypoid Gear-Drives of Formate and Helixform," Journal of Mechanical Design, 103: 83-113, 1981.

3. Litvin, F.L.: Theory of Gearing (in Russian), 1st ed. in 1960, 2nd ed. in 1968.

4. Litvin, F.L.: Gear Geometry and Applied Theory, Prentice Hall, Englewood Cliffs, NJ, 1994.

5. Litvin, F.L. et al.: "Computerized Design and Generation of Low-Noise Helical Gears with Modified Surface Topology," Journal of Mechanical Design, 117: 254-261, 1995.

6. Stadtfeld, H.J: Handbook of Bevel and Hypoid Gear, Rochester Institute of Technology, 1993. 


\section{APPENDIX 1. EQUATIONS OF PINION AND GEAR TOOTH SURFACES}

The equations presented in Litvin, F.L., 1994 for tooth surfaces of helical involute gears and the coordinate systems are used. The tooth side surface Il $\left(\Sigma_{1}\right)$ of a left-hand pinion (see the cross-section in Fig. A.1.10) and the unit nomal $\mathbf{n}_{1}$ to the surface are represented as follows:

$$
\begin{gathered}
\mathbf{r}_{1}\left(u_{1}, \theta_{1}\right)=\left[\begin{array}{c}
r_{b 1} \cos \left(\theta_{1}+\mu_{1}\right)+u_{1} \cos \lambda_{b 1} \sin \left(\theta_{1}+\mu_{1}\right) \\
-r_{b 1} \sin \left(\theta_{1}+\mu_{1}\right)+u_{1} \cos \lambda_{b 1} \cos \left(\theta_{1}+\mu_{1}\right) \\
-u_{1} \sin \lambda_{b 1}+p_{1} \theta_{1}
\end{array}\right] \\
\mathbf{n}_{1}\left(q_{1}\right)=\left[\begin{array}{c}
-\sin \lambda_{b 1} \sin \left(q_{1}+m_{1}\right) \\
-\sin \lambda_{b 1} \cos \left(q_{1}+m_{1}\right) \\
-\cos \lambda_{b 1}
\end{array}\right]
\end{gathered}
$$

The surface tooth side II $\left(\Sigma_{2}\right)$ of a right-had gear (see the cross-section in Fig. A.1.2) and the unit normal $\mathbf{n}_{2}$ to the surface are represented by the equations

$$
\begin{gathered}
\mathbf{r}_{2}\left(u_{2}, \theta_{2}\right)=\left[\begin{array}{c}
r_{b 2} \cos \left(\theta_{2}-\eta_{2}\right)+u_{2} \cos \lambda_{b 2} \sin \left(\theta_{2}-\eta_{2}\right) \\
-r_{b 2} \sin \left(\theta_{2}-\eta_{2}\right)+u_{2} \cos \lambda_{b 2} \cos \left(\theta_{2}-\eta_{2}\right) \\
u_{2} \sin \lambda_{b 2}-p_{2} \theta_{2}
\end{array}\right] \\
\mathbf{n}_{2}\left(\theta_{2}\right)=\left[\begin{array}{c}
\sin \lambda_{b 2} \sin \left(\theta_{2}-\eta_{2}\right) \\
\sin \lambda_{b 2} \cos \left(\theta_{2}-\eta_{2}\right) \\
-\cos \lambda_{b 2}
\end{array}\right]
\end{gathered}
$$

Here: $\left(u_{i}, q_{i}\right)(i=1,2)$ are the surface parameters. The relationships between the design parameters are represented in Appendix 2 and their notations are given in the nomenclature.

For simulation of meshing coordinate systems $S_{1}$ and $S_{2}$ that are rigidly connected to pinion 1 and gear 2, respectively (Fig. A.1.3) are applied. The meshing of the gear tooth surfaces is considered in the fixed coordinate system $S_{f}$ that is rigidly connected to the housing. Coordinate system $S_{p}$ is an auxiliary fixed coordinate system. Coordinate system $S_{q}$ is applied to simulate the errors of assembly (Fig. A.1.3).

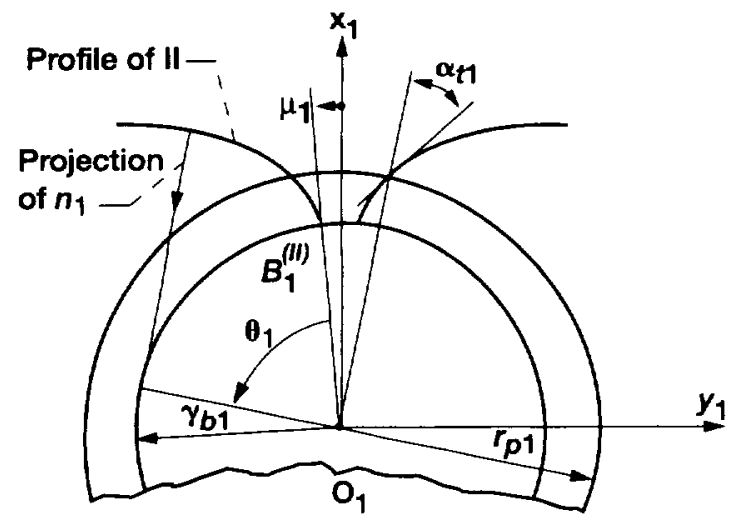

Figure A.1.1.-Cross section of helical pinion (1).

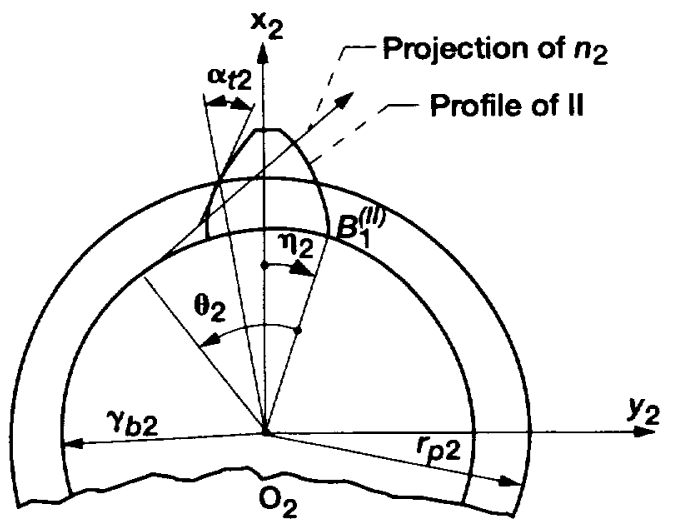

Figure A.1.2.-Cross section of helical gear (2). 


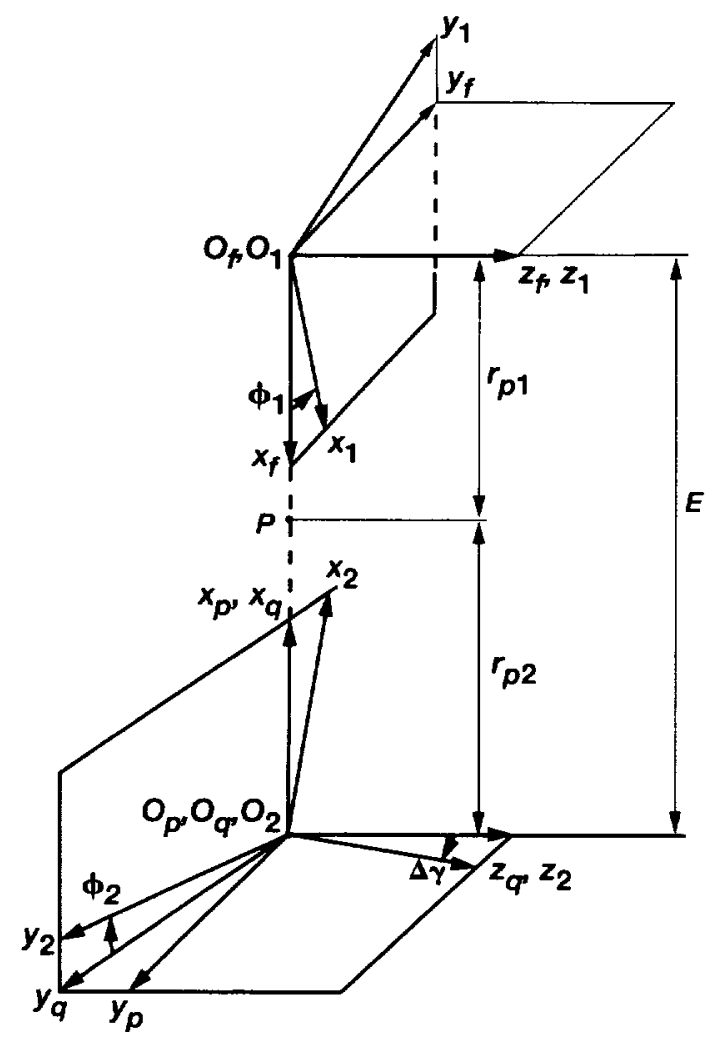

Figure A.1.3.-Applied coordinate system. 


\section{APPENDIX 2.-RELATIONS BETWEEN THE DESIGN PARAMETERS}

The input design parameters are : $N_{1}, N_{2}, P_{n}, \alpha_{n}$, and $\lambda_{p}$. For ideal gearing we have: $\alpha_{n 1}=\alpha_{n 2}, \lambda_{p 1}=\lambda_{p 2}, \lambda_{b 1}=\lambda_{b 2}$. The remaining design parameters (see the nomenclature) are determined as follows

$$
\begin{gathered}
\tan \alpha_{t i}=\frac{\tan \alpha_{n i}}{\sin \lambda_{p i}},(i=1,2) \\
p_{t i}=\frac{\pi}{P_{n} \sin \lambda_{p i}}
\end{gathered}
$$

$w_{t 1}=\frac{P_{n}}{2}$ (assuming that the backlash is zero) $($ A.2.3)

$$
\begin{gathered}
s_{t 2}=\frac{P_{t 2}}{2} \\
r_{p i}=\frac{N_{i}}{2 P_{n} \sin \lambda_{p i}} \\
r_{b i}=r_{p i} \cos \alpha_{t i} \\
\tan \lambda_{b i}=\frac{\tan \lambda_{p i}}{\cos \alpha_{t i}} \\
p_{i}=\eta_{b i} \tan \lambda_{b i}=r_{p i} \tan \lambda_{p i} \\
H_{i}=2 \pi_{p i} \\
\frac{p_{1}}{p_{2}}=\frac{r_{b 1}}{r_{b 2}}=\frac{r_{p 1}}{r_{p 2}}=\frac{N_{1}}{N_{2}}=m_{21}
\end{gathered}
$$




\section{APPENNDIX 3.-ALGORITHM OF TCA FOR ALIGNED GEARS}

The TCA computer program requires the solution of the system of Eq. (3). The algorithm developed is based on computation by the following steps:

Step 1: In the case of aligned gears we have

$$
\lambda_{b 1}=\lambda_{b 2}=\lambda_{b}
$$

Step 2: Considering $n_{x f}^{(1)}=n_{x f}^{(2)}$ and $n_{y f}^{(1)}=n_{y f}^{(2)}$, we obtain the equation

$$
\theta_{1}+\mu_{1}-\phi_{1}=\theta_{2}-\eta_{2}+\phi_{2}
$$

where $f_{1}$ is the input parameter.

Step 3: Considering $x_{f}^{(1)}=x_{f}^{(2)}$ and Eqs. (A.3.1) to (A.3.2), we obtain

$$
\begin{array}{r}
\left(r_{b 1}+r_{b 2}\right) \cos \left(\theta_{1}+\mu_{1}-\phi_{1}\right)+\left(u_{1}+u_{2}\right) \\
\times \cos \lambda_{b} \sin \left(\theta_{1}+\mu_{1}-\phi_{1}\right)=\mathrm{E}
\end{array}
$$

Step 4: Considering $y_{f}^{(1)}=y_{f}^{(2)}$ and Eqs. (A.3.1) to (A.3.2), we obtain

$$
\begin{array}{r}
\left(r_{b 1}+r_{b 2}\right) \sin \left(\theta_{1}+\mu_{1}-\phi_{1}\right)+\left(u_{1}+u_{2}\right) \\
\times \cos \lambda_{b} \cos \left(\theta_{1}+\mu_{1}-\phi_{1}\right)=0
\end{array}
$$

Step 5: Considering $z_{f}^{(1)}=z_{f}^{(2)}$ and Eq. (A.3.1), we obtain

$$
\left(u_{1}+u_{2}\right) \sin \lambda_{b}-p_{1} \theta_{1}-p_{2} \theta_{2}=0
$$

Step 6: Equations (A.3.3) and (A.3.4) yield

$$
\theta_{1}=\alpha_{t}+\phi_{1}-\mu_{1}
$$

Step 7: Equations (A.3.4) and (A.3.5) yield

$$
\theta_{2}=\left(\frac{N_{1}}{N_{2}}+1\right) \tan \alpha_{t}-\frac{N_{1}}{N_{2}} \theta_{1}
$$

Step 8: Equations (A.3.2) and (A.3.6) yield

$$
\phi_{2}=\eta_{2}-\theta_{2}+\alpha_{t}
$$

Step 9: Equation (A.3.5) yields

$$
u_{2}=\frac{r_{b 1} \theta_{1}+r_{b 2} \theta_{2}}{\cos \lambda_{b}}-u_{1}
$$

Note: parameter $u_{1}$ is the second input parameter, in addition to $\phi_{1}$, that is required for the TCA for aligned gears. 


\section{APPENDIX 4.-TCA ALGORITHM FOR MISALIGNED GEAR DRIVES}

An initial guess is required for the solution of equation system (3) in the case of gear misalignment. The required set of parameters, $P^{(0)}=\left(u_{1}^{(0)}, \theta_{1}^{(0)}, \phi_{1}^{(0)}, u_{2}^{(0)}, \theta_{2}^{(0)}, \phi_{2}^{(0)}\right)$, can be obtained by the following derivations

Step 1: Using equation $n_{z f}^{(1)}=n_{z f}^{(2)}$, we obtain

$$
\begin{array}{r}
\cos \Phi_{2}=\frac{\cos \lambda_{b 1}-\cos \lambda_{b 2} \cos \Delta \gamma}{\sin \lambda_{b 2} \sin \Delta \gamma} \\
\left(\Phi_{2}=\theta_{2}-\eta_{2}+\phi_{2}\right)
\end{array}
$$

We consider that when pinion lead angle error, $\mathrm{Dl}_{p 1}$, occurs, we have $\lambda_{b 1} \neq \lambda_{b 2}$ and $\lambda_{p 1} \neq \lambda_{p 2}$ (see Appendix 2).

Step 2: Using equation $n_{x f}^{(1)}=n_{x f^{(2)}}$ we obtain

$$
\sin \Phi_{1}=\frac{\sin \lambda_{b 2}}{\sin \lambda_{b 1}} \sin \Phi_{2},\left(\Phi_{1}=\theta_{1}+\mu_{1}-\phi_{1}\right)
$$

Step 3: Using equation $x_{f}^{(1)}=x_{f}^{(2)}$, we obtain

$$
u_{2}=\frac{1}{\cos \lambda_{b 2} \sin \Phi_{2}}\left(E-r_{b 2} \cos \Phi_{2}-x_{f}^{(1)}\right)
$$

Step 4: Using equation $y_{f}^{(1)}=y_{f}^{(2)}$, we obtain

$$
\begin{aligned}
\theta_{2} & =\frac{1}{p_{2} \sin \Delta \gamma}\left[y_{f}^{(1)}+u_{2} \sin \lambda_{b 2} \sin \Delta \gamma\right. \\
& \left.-\left(r_{b 2} \sin \Phi_{2}-u_{2} \cos \lambda_{b 2} \cos \Phi_{2}\right) \cos \Delta \gamma\right]
\end{aligned}
$$

Step 5: Using equaton $z_{f}^{(1)}=z_{f}^{(2)}$, we obtain

$$
\theta_{1}=\frac{1}{p_{1}}\left(z_{f}^{(2)}+u_{1} \sin \lambda_{b 1}\right)
$$

Step 6: Equation (A.4.2) yields

$$
\phi_{1}=\theta_{1}+\mu_{1}-\Phi_{1}
$$

Step 7: Equations (A.4.1) and (A.4.2) yield

$$
\phi_{2}=\Phi_{2}-\boldsymbol{\theta}_{2}+\eta_{2}
$$

When $u_{1}$ is chosen, the other five parameters may be determined by Eqs. (A.4.3) to (A.4.7). Parameter $u_{1}$ is related with the magnitude $r_{1}$ of the position vector of the pinion cross-section by the equation 


$$
u_{1}=\frac{\sqrt{r_{1}^{2}-r_{b 1}^{2}}}{\cos \lambda_{b 1}}
$$

where $r_{d 1} \leq r_{1} \leq r_{a 1}$.

Equations (A.4.3) to (A.4.5) and (A.4.7) to (A.4.8) permit one to determine parameters $P^{(0)}$ as the initial guess for the solution of the system of Eq. (3) considering that $f_{1}$ is given. 


\section{APPENDIX 5.-SURFACES OF TOOTH RACK-CUTTERS}

As a reminder, that two rack-cutters are applied for the separate generation of the gear and the pinion (Fig. 11(a)). The gear rack-cutter is a conventional one that is used for generation of involute gears and its normal section is represented in $S_{c 2}$ (Fig. 11(c)) as

$$
r_{c 2}\left(u_{t}\right)=\mathbf{M}_{c 2 b} r_{b}\left(u_{t}\right)=\left[\begin{array}{c}
u_{t} \cos \alpha_{n} \\
a_{m}-u_{t} \sin \alpha_{n} \\
0 \\
1
\end{array}\right]
$$

where (Fig. 11(c))

$$
a_{m}=\frac{\pi}{4 P_{n}}, \mathbf{r}_{b}\left(u_{b}\right)=\left[\begin{array}{llll}
-u_{t} & 0 & 0 & 1
\end{array}\right]^{T}
$$

The equations of the surface and the unit normal to the surface of gear rack-cutter $\Sigma_{t}$ are represented in $S_{t}$ as

$$
\begin{gathered}
\mathbf{r}_{t}\left(u_{t}, l_{t}\right)=\mathbf{M}_{t c 2} \mathbf{r}_{c 2}\left(u_{t}\right) \\
\mathbf{n}_{t}=\frac{\frac{\partial \mathbf{r}_{t}}{\partial l_{t}} \times \frac{\partial \mathbf{r}_{t}}{\partial u_{t}}}{\left|\frac{\partial \mathbf{r}_{t}}{\partial l_{t}} \times \frac{\partial \mathbf{r}_{t}}{\partial u_{t}}\right|}
\end{gathered}
$$

where (Fig. A.5.1(b))

$$
M_{t c 2}=\left[\begin{array}{cccc}
1 & 0 & 0 & 0 \\
0 & \cos \beta & \sin \beta & l_{t} \sin \beta \\
0 & -\sin \beta & \cos \beta & l_{t} \cos \beta \\
0 & 0 & 0 & 1
\end{array}\right]
$$

For the purpose of localization of contact, the normal section of pinion rack-cutter deviates from the normal section of the gear rack-cutter and is represented in $S_{c 1}$ as (Fig. 11(b))

$$
\mathbf{r}_{c 1}\left(u_{c}\right)=\mathbf{M}_{c 1 b} \mathbf{r}_{b}\left(u_{c}\right)=\left[\begin{array}{c}
-u_{c} \cos \alpha_{n}-a_{c} u_{c}^{2} \sin \alpha_{n} \\
u_{c} \sin \alpha_{n}-a_{c} u_{c}^{2} \cos \alpha_{n}-\alpha_{m} \\
0 \\
1
\end{array}\right] \text { (A.5.6) }
$$
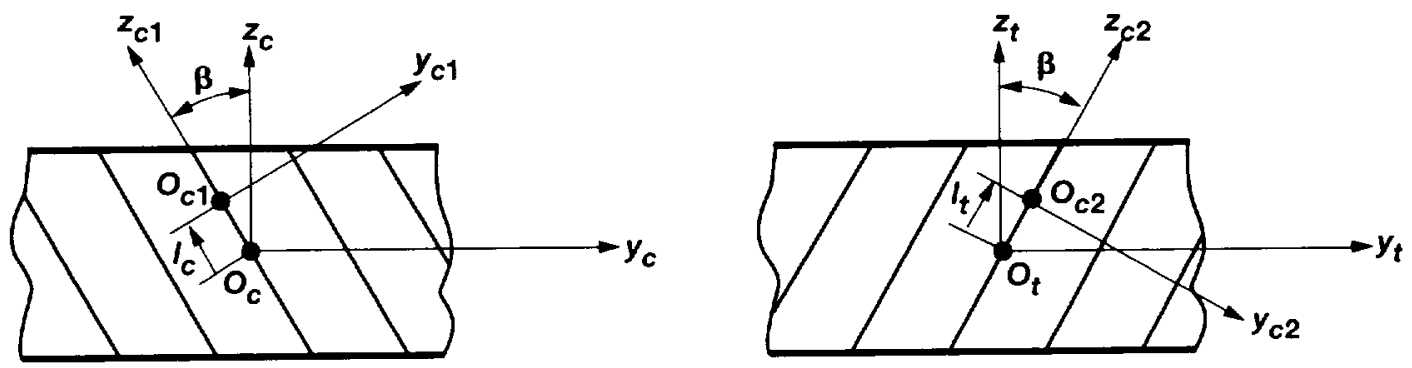

Figure A.5.1.-To derivation of rack-cutter surface. 
where

$$
\mathrm{r}_{b}\left(u_{c}\right)=\left[\begin{array}{llll}
-u_{c}-a_{c} u_{c}^{2} & 0 & 1
\end{array}\right]^{T}
$$

The surface equation of pinion rack-cutter $\Sigma_{c}$ is represented in $S_{c}$

$$
\mathbf{r}_{c}\left(u_{c}, l_{c}\right)=\mathbf{M}_{c c 1} r_{c 1}\left(u_{c}\right)
$$

where (Fig. A.5.1(a))

$$
M_{c c 1}=\left[\begin{array}{cccc}
1 & 0 & 0 & 0 \\
0 & \cos \beta & -\sin \beta & -l_{c} \sin \beta \\
0 & -\sin \beta & \cos \beta & l_{c} \cos \beta \\
0 & 0 & 0 & 1
\end{array}\right]
$$

The unit normal to $\Sigma_{c}$ is represented in $S_{c}$ by equations

$$
\mathbf{n}_{c}=\frac{\mathbf{N}_{c}}{\left|\mathbf{N}_{c}\right|}, \mathbf{N}_{c}=\frac{\partial \mathbf{r}_{c}}{\partial l_{c}} \times \frac{\partial \mathbf{r}_{c}}{\partial u_{c}}
$$

that yield

$$
\mathbf{n}_{c}=\frac{1}{\sqrt{1+4 a_{c}^{2} u_{c}^{2}}}\left[\begin{array}{c}
-\sin \alpha_{n}+2 a_{c} u_{c} \cos \alpha_{n} \\
-\left(\cos \alpha_{n}+2 a_{c} u_{c} \cos \alpha_{n}\right) \cos \beta \\
-\left(\cos \alpha_{n}+2 a_{c} u_{c} \cos \alpha_{n}\right) \cos \beta
\end{array}\right]
$$

\section{Equation of Meshing}

In the process for the generation, the two rigidly connected rack-cutters perform translational motion, while the pinion and gear perform rotational motions as shown in Fig. A.5.2.

The equation of meshing between surface $\Sigma_{r}(r=c, t)$ of the rack-cutter and the pinion (gear) tooth surface $\sum_{i}(i=1,2)$ can be represented as
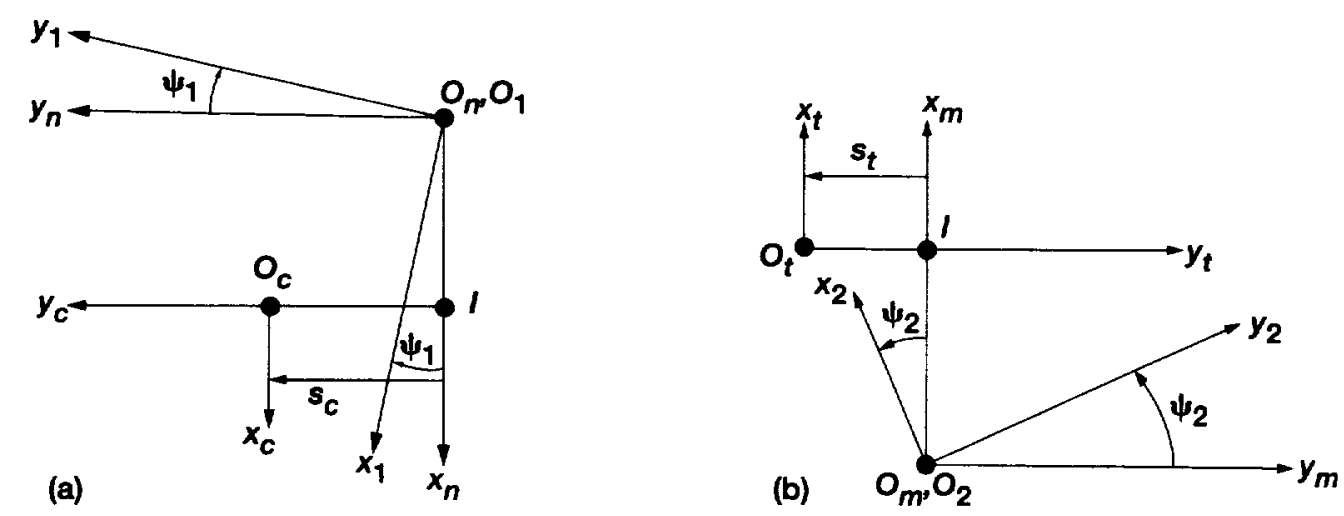

Figure A.5.2.-Generation of pinion and gear by rack-cutters. 


$$
f\left(u_{r}, l_{r}, \psi_{l}\right)=0
$$

where $y_{i}$ is the angle of rotation of the gear in the process for generation. The derivation of equation of meshing is based on the theorem that the common normal to $\sum_{r}$ and $\sum_{i}$ must pass through the instantaneous axis of rotaton. Thus, we have

$$
\frac{X_{r}-x_{r}}{n_{x r}}=\frac{Y_{r}-y_{r}}{n_{y r}}=\frac{Z_{r}-z_{r}}{n_{z r}}
$$

Here (Fig. A.5.2) we have

(i) $\left(X_{t}=0, Y_{t}=r_{p 2} y_{2}\right)$ in the case for gear generation.

(ii) $\left(X_{c}=0, Y_{c}=-r_{p 1} y_{1}\right)$ in the case for pinion generation.

After transformations, we obtain the following equations of meshing between $\Sigma_{1}$ and $\Sigma_{c}$, and $\Sigma_{2}$ and $\Sigma_{t}$, respectively

$$
\begin{array}{r}
f\left(u_{c}, l_{c}, \psi_{1}\right)=r_{p 1} \psi_{1}-l_{c} \sin \beta-a_{m} \cos \beta \\
+\frac{u_{c}\left(1+2 a_{c}^{2} u_{c}^{2}\right) \cos \beta}{\sin \alpha_{n}-2 a_{c} u_{c} \cos \alpha_{n}}=0 \\
f\left(u_{t}, l_{c}, \psi_{2}\right)=r_{p 2} \psi_{2}-l_{t} \sin \beta-a_{m} \cos \beta \\
+\frac{u_{t} \cos \beta}{\sin \alpha_{n}}=0
\end{array}
$$

where $\psi_{i}(i=1,2)$ is the angle of pinion and gear rotation.

\section{Tooth Surfaces}

Pinion tooth surface $\Sigma_{1}$ is generated by rack-cutter tooth surface $\Sigma_{c}$ and is represented in $S_{1}$ by the equations

$$
\mathbf{r}_{1}\left(u_{c}, l_{c}, \psi_{1}\right)=\mathbf{M}_{1 n} \mathbf{M}_{n c} \mathbf{r}_{c}\left(u_{c}, l_{c}\right), f\left(u_{c}, l_{c}, \psi_{1}\right)=0
$$

where (Fig. A.5.2(a))

$$
\begin{gathered}
M_{1 n}=\left[\begin{array}{cccc}
\cos \psi_{1} & \sin \psi_{1} & 0 & 0 \\
-\sin \psi_{1} & \cos \psi_{1} & 0 & 0 \\
0 & 0 & 1 & 0 \\
0 & 0 & 0 & 1
\end{array}\right] \\
M_{n c}=\left[\begin{array}{cccc}
1 & 0 & 0 & r_{p 1} \\
0 & 1 & 0 & r_{p 1 \psi_{1}} \\
0 & 0 & 1 & 0 \\
0 & 0 & 0 & 1
\end{array}\right]
\end{gathered}
$$

Gear tooth surface $\Sigma_{2}$ is represented in $S_{2}$ by the following equation

$$
\mathbf{r}_{2}\left(u_{c}, l_{c}, \psi_{2}\right)=\mathbf{M}_{2 n} \mathbf{M}_{m t} \mathbf{r}_{t}\left(u_{t}, l_{t}\right), f\left(u_{t}, l_{t}, \psi_{2}\right)=0
$$


where (Fig. A.5.2(b))

$$
\begin{gathered}
M_{2 m}=\left[\begin{array}{cccc}
\cos \psi_{2} & -\sin \psi_{2} & 0 & 0 \\
\sin \psi_{2} & \cos \psi_{2} & 0 & 0 \\
0 & 0 & 1 & 0 \\
0 & 0 & 0 & 1
\end{array}\right] \\
M_{m t}=\left[\begin{array}{cccc}
1 & 0 & 0 & r_{p 2} \\
0 & 1 & 0 & -r_{p 2 \psi_{2}} \\
0 & 0 & 1 & 0 \\
0 & 0 & 0 & 1
\end{array}\right]
\end{gathered}
$$





\begin{tabular}{|c|c|c|c|}
\hline \multicolumn{3}{|c|}{ REPORT DOCUMENTATION PAGE } & $\begin{array}{l}\text { Form Approved } \\
\text { OMB No. 0704-0188 }\end{array}$ \\
\hline \multicolumn{4}{|c|}{ 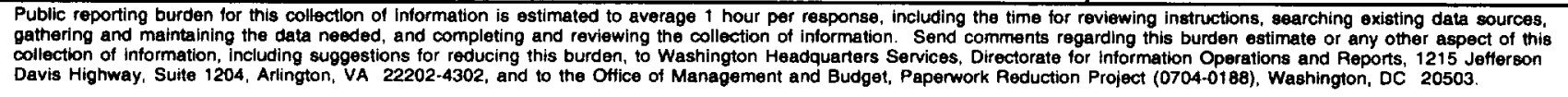 } \\
\hline 1. AGENCY USE ONLY (Leave blank) & \multicolumn{2}{|l|}{$\begin{array}{r}\text { 2. REPORT DATE } \\
\text { July } 1997\end{array}$} & $\begin{array}{l}\text { SCOVERED } \\
\text { Memorandum }\end{array}$ \\
\hline \multicolumn{3}{|c|}{$\begin{array}{l}\text { 4. TITLE AND SUBTITLE } \\
\text { Computerized Simulation of Meshing of Conventional Helical Involute Gears } \\
\text { and Modification of Geometry }\end{array}$} & \multirow{2}{*}{$\begin{array}{l}\text { 5. FUNDING NUMBERS } \\
\text { WU-581-30-13 } \\
\text { 1L162211 A47A }\end{array}$} \\
\hline \multicolumn{3}{|c|}{$\begin{array}{l}\text { 6. AUTHOR(S) } \\
\text { F.L. Litvin, J. Lu, D.P. Townsend, and M. Hawkins }\end{array}$} & \\
\hline \multicolumn{3}{|l|}{$\begin{array}{l}\text { NASA Lewis Research Center } \\
\text { Cleveland, Ohio } 44135-3191 \\
\text { and } \\
\text { U.S. Army Research Laboratory } \\
\text { Cleveland, Ohio } 44135-3191\end{array}$} & $\begin{array}{l}\text { 8. PERFORMING ORGANIZATION } \\
\text { REPORT NUMBER }\end{array}$ \\
\hline \multicolumn{3}{|c|}{$\begin{array}{l}\text { 9. SPONSORINGMONITORING AGENCY NAME(S) AND ADDRESS(ES) } \\
\text { National Aeronautics and Space Administration } \\
\text { Washington, DC 20546-0001 } \\
\text { and } \\
\text { U.S. Army Research Laboratory } \\
\text { Adelphi, Maryland 20783-1145 }\end{array}$} & $\begin{array}{l}\text { 10. SPONSORINGMONITORING } \\
\text { AGENCY REPORT NUMBER }\end{array}$ \\
\hline \multicolumn{4}{|c|}{$\begin{array}{l}\text { 11. SUPPLEMENTARY NOTES } \\
\text { F.L. Litvin and J. Lu, University of Illinois at Chicago, Chicago, Illinois } 60680 \text { (work funded under NASA Grant NAG3- } \\
\text { 1822); D.P. Townsend, NASA Lewis Research Center; and M. Hawkins, Allison Engine Company, Indianapolis, Indiana } \\
\text { 46206. Responsible person, D.P. Townsend, organization code 5950, (216) } 433-3955 \text {. }\end{array}$} \\
\hline \multicolumn{3}{|c|}{$\begin{array}{l}\text { 12a. DISTRIBUTION/AVAILABILTY STATEMENT } \\
\text { Unclassified - Unlimited } \\
\text { Subject Category } 37 \\
\text { This publication is available from the NASA Center for AeroSpace Information, (301) 621-0390. }\end{array}$} & 12b. DISTRIBUTION CODE \\
\hline \multicolumn{4}{|c|}{ 13. ABSTRACT (Maximum 200 words) } \\
\hline \multirow{2}{*}{\multicolumn{3}{|c|}{$\begin{array}{l}\text { 14. SUBJECT TERMS } \\
\text { Gear; Geometry; TCA; Transmission error; Helical; Spiral bevel; Hypoid }\end{array}$}} & $\begin{array}{c}\text { 15. NUMBER OF PAGES } \\
22\end{array}$ \\
\hline & & & $\begin{array}{l}\text { 16. PRICE CODE } \\
\text { A03 }\end{array}$ \\
\hline $\begin{array}{l}\text { 17. SECURITY CLASSIFICATION } \\
\text { OF REPORT } \\
\text { Unclassified }\end{array}$ & $\begin{array}{l}\text { 18. SECURITY CLASSIFICATION } \\
\text { OF THIS PAGE } \\
\text { Unclassified }\end{array}$ & $\begin{array}{l}\text { 19. SECURITY CLASSIFICATION } \\
\text { OF ABSTRACT } \\
\text { Unclassified }\end{array}$ & 20. LIMITATION OF ABSTRACT \\
\hline NSN 7540-01-280-5500 & & & $\begin{array}{l}\text { andard Form } 298 \text { (Rev. 2-89) } \\
\text { escribed by ANSI Std. Z39-18 } \\
\text { 8-102 }\end{array}$ \\
\hline
\end{tabular}

